\title{
The influences of PRG-1 on the expression of small RNAs and mRNAs
}

\author{
Jia-Jia Wang ${ }^{1,2+}$, Dong-Ya Cui ${ }^{1,2,4+}$, Tengfei Xiao ${ }^{3+}$, Xubin Sun ${ }^{1,2}$, Peng Zhang ${ }^{2}$, Runsheng Chen ${ }^{3 *}$, \\ Shunmin $\mathrm{He}^{2^{*}}$ and Da-Wei Huang ${ }^{1,2^{*}}$
}

\begin{abstract}
Background: In metazoans, Piwi-related Argonaute proteins play important roles in maintaining germline integrity and fertility and have been linked to a class of germline-enriched small RNAs termed piRNAs. Caenorhabditis elegans encodes two Piwi family proteins called PRG-1 and PRG-2, and PRG-1 interacts with the C. elegans piRNAs (21U-RNAs). Previous studies found that mutation of prg-1 causes a marked reduction in the expression of 21U-RNAs, temperaturesensitive defects in fertility and other phenotypic defects.

Results: In this study, we wanted to systematically demonstrate the function of PRG-1 in the regulation of small RNAs and their targets. By analyzing small RNAs and mRNAs with and without a mutation in prg-1 during C. elegans development, we demonstrated that (1) mutation of prg-1 leads to a decrease in the expression of $21 \mathrm{U}-\mathrm{RNAs}$, and causes $35 \sim 40 \%$ of miRNAs to be down-regulated; (2) in C. elegans, approximately 3\% (6\% in L4) of protein-coding genes are differentially expressed after mutating prg-1, and $60 \sim 70 \%$ of these substantially altered protein-coding genes are up-regulated; (3) the target genes of the down-regulated miRNAs and the candidate target genes of the down-regulated 21U-RNAs are enriched in the up-regulated protein-coding genes; and (4) PRG-1 regulates protein-coding genes by down-regulating small RNAs (miRNAs and 21U-RNAs) that target genes that participate in the development of $C$. elegans.
\end{abstract}

Conclusions: In prg-1-mutated C. elegans, the expression of miRNAs and 21U-RNAs was reduced, and the protein-coding targets, which were associated with the development of $C$. elegans, were up-regulated. This may be the mechanism underlying PRG-1 function.

Keywords: C. elegans, miRNAs, 21U-RNAs

\section{Background}

Small non-coding RNAs, including microRNAs (miRNAs), Piwi-interacting RNAs (piRNAs), endogenoussiRNAs (endo-siRNAs) and others, play important roles in controlling gene expression. These small RNAs interact with different types of Argonaute proteins to form complexes, such as the RNA-induced silencing complex (RISC) [1-4]. These complexes recognize target genes via complementary base pairing and regulate the target genes' expression. The Caenorhabditis elegans genome is currently known to encode 24 Argonaute proteins [5],

\footnotetext{
*Correspondence: crs@sun5.ibp.ac.cn; heshunmin@gmail.com; huangdw@ioz.ac.cn ${ }^{\dagger}$ Equal contributors

${ }^{3}$ Laboratory of Bioinformatics and Noncoding RNA, Institute of Biophysics, Chinese Academy of Sciences, Beijing 100101, People's Republic of China ${ }^{2}$ Key Laboratory of Zoological Systematics and Evolution, Institute of Zoology, Chinese Academy of Sciences, Beijing 100101, People's Republic of China 'School of Life Science, Hebei University, Hebei 071002, People's Republic of China Full list of author information is available at the end of the article
}

which are divided into three subcategories based on homology and the small RNAs with which they interact: (1) PIWIs, which interact with the 21U-RNAs, or piRNAs; (2) Argonautes, two of which have been shown to interact with miRNAs, and two of which have been shown to interact with 26G-RNAs; and (3) the worm Argonautes (WAGOs), which interact with 22G-RNAs [6-16].

In C. elegans, two Piwi-related proteins, PRG-1 and PRG-2, have been identified. Loss of PRG-1 can cause germline defects and temperature-sensitive sterility $[8,17]$. 21U-RNAs, the piRNAs of C. elegans, are precisely $21 \mathrm{nu}-$ cleotides long which are shorter than piRNAs in flies and mammals, have a bias for uracil $5^{\prime}$ monophosphate and have a modified $3^{\prime}$ end that resists periodate-degradation [7,8,18-22]. 21U-RNAs are expressed in the germline. Their genomic loci disperse in two broad regions of chromosome IV [18], and their accumulation depends on 
the wild-type activity of PRG-1. Mutation of prg-1 causes decreased expression of 21U-RNAs [8,17].

C. elegans has complex interactions within its regulatory network. We would therefore expect, that some small RNAs other than 21U-RNAs, such as miRNAs and endosiRNAs, are influenced directly or indirectly by PRG-1. To study whether PRG-1 can influence the expression of other small RNAs and regulate protein-coding genes via small RNAs, we extracted small RNAs from six developmental stages (embryo, L1, L2, L3, L4 and young adult) and mRNAs from four developmental stages (L1, L2, L3 and L4) of prg-1-mutant C. elegans for high-throughput sequencing. We obtained wild-type data of small RNAs and mRNAs from the corresponding stages from the NCBI database $[8,23]$. We analyzed the wild-type and mutant prg-1 data and demonstrated the function of PRG-1.

\section{Results}

We extracted small RNAs from six developmental stages (embryo, L1, L2, L3, L4, and young adult) and mRNAs from four stages (L1, L2, L3 and L4) of prg-1 mutants. High-throughput sequencing of small RNA samples produced 52,363,338 reads that mapped to the C. elegans genome. Sequencing of mRNA samples produced 48,257,011 mappable reads. The numbers of small RNA and mRNA reads there were generated at each stage are shown in Table 1.

The influence of PRG-1 on the composition of small RNAs In C. elegans, small RNAs can be classified by their Argonaute-binding partners [24]. The expression of small RNAs, including miRNAs and 21U-RNAs, changes during development [25]. To test whether the composition of small RNAs in different stages are affected by PRG-1, we analyzed the composition of small RNAs with and without a prg-1 mutation.

In wild-type C. elegans (Figure 1A), the percent of small RNAs that are 21U-RNAs gradually increased along with development, from $0.72 \%$ in $\mathrm{L} 1$ to $7.16 \%$ in young adults. However, the expression of 21U-RNAs decreased from L1

Table 1 Summary of the RNA-seq data

\begin{tabular}{ccc}
\hline \multirow{2}{*}{ Stage } & \multicolumn{2}{c}{ Mappable reads } \\
\cline { 2 - 3 } & Small RNA & mRNA \\
\hline Embryo & $8,056,943$ & $11,794,170$ \\
L1 & $8,867,568$ & $11,842,726$ \\
L2 & $8,632,646$ & $12,222,134$ \\
L3 & $8,970,579$ & $12,397,981$ \\
Young adult & $8,941,933$ & \\
Total reads & $8,893,669$ & $48,257,011$ \\
\hline
\end{tabular}

The reads of small RNAs for six stages (embryo, L1, L2, L3, L4, and young adult) and mRNAs for four stages (L1, L2, L3, and L4) in the prg-1 mutant. to L2; and the reasons behind this differential expression are described below. Like the 21U-RNAs, the proportion of 22G-like small RNAs, which are 22 nucleotides long and have a 5 '-G, gradually increased from $0.08 \%$ in L1 to $0.37 \%$ in young adults. Along with the development, $21 \mathrm{U}$ RNAs and 22G-like small RNAs Spearman's rank correlation is 0.771 . This indicated that 21U-RNAs and 22Glike small RNAs may have a positive correlation.

However, 21U-RNAs could barely be detected in prg-1 mutants (Figure 1B), which was consistent with previous reports. Interestingly, 22G-like small RNAs also tended to increase throughout the growth period, but the rate of increase was smaller than in the wild type.

miRNAs were highly expressed and had absolute dominance in all developmental stages in the wild type and prg-1 mutant. The proportion of small RNAs that were 26 nucleotides long and had a $5^{\prime}-\mathrm{G}$, termed 26G-like small RNAs, decreased gradually during early development. Inversely, these RNAs exhibited a slight increase in late development. In wild type, the Spearman's correlation of 22G-like small RNAs and 26G-like small RNAs is 0.486 , so there is weaker correlation between 22G-like small RNAs and 26G-like small RNAs.

\section{Mutation of prg-1 induced a decrease in $35 \sim 40 \%$ of miRNAs}

miRNAs are well characterized in C. elegans [18,24-29]. Mature miRNAs associate with the Argonautes proteins ALG-1 and ALG-2 [9]. However, it is not clear whether PRG-1 affects miRNAs. To explore whether mutation of prg-1 affected miRNAs, we used the miRDeep 2 program [30] to identify known miRNAs from all developmental stages. DEGseq [31] and GFOLD [32] were used to analyze miRNA expression at the same developmental stages in the presence or absence of a prg-1 mutation, and the differential expression miRNAs were defined in 'Methods'.

Approximately $50 \%$ of the known miRNAs exhibited changes in expression at the same stage when in the presence and absence of a prg-1 mutation (Additional file 1: Table S1). At each stage, 35\% 40\% of miRNAs showed a decrease (Figure 2A). The results indicated that PRG-1 affects miRNA expression. Many known miRNAs were decreased in the prg-1 mutant. Therefore, PRG-1 plays an important role in regulating miRNA expression.

The read count of each miRNA differs between developmental stages; therefore it is reasonable to conclude that miRNA expression is stage-specific [25]. As mentioned above, some miRNAs exhibited a decrease in each stage after mutation of prg-1. The decreased miRNAs were stage-specific or general. To determine whether the effect of PRG-1 on miRNAs at different stages was specific, we performed further analysis of the decreased miRNAs in six stages. As exhibited in Figure 2B, most down-regulated miRNAs are shown to decrease in all developmental 


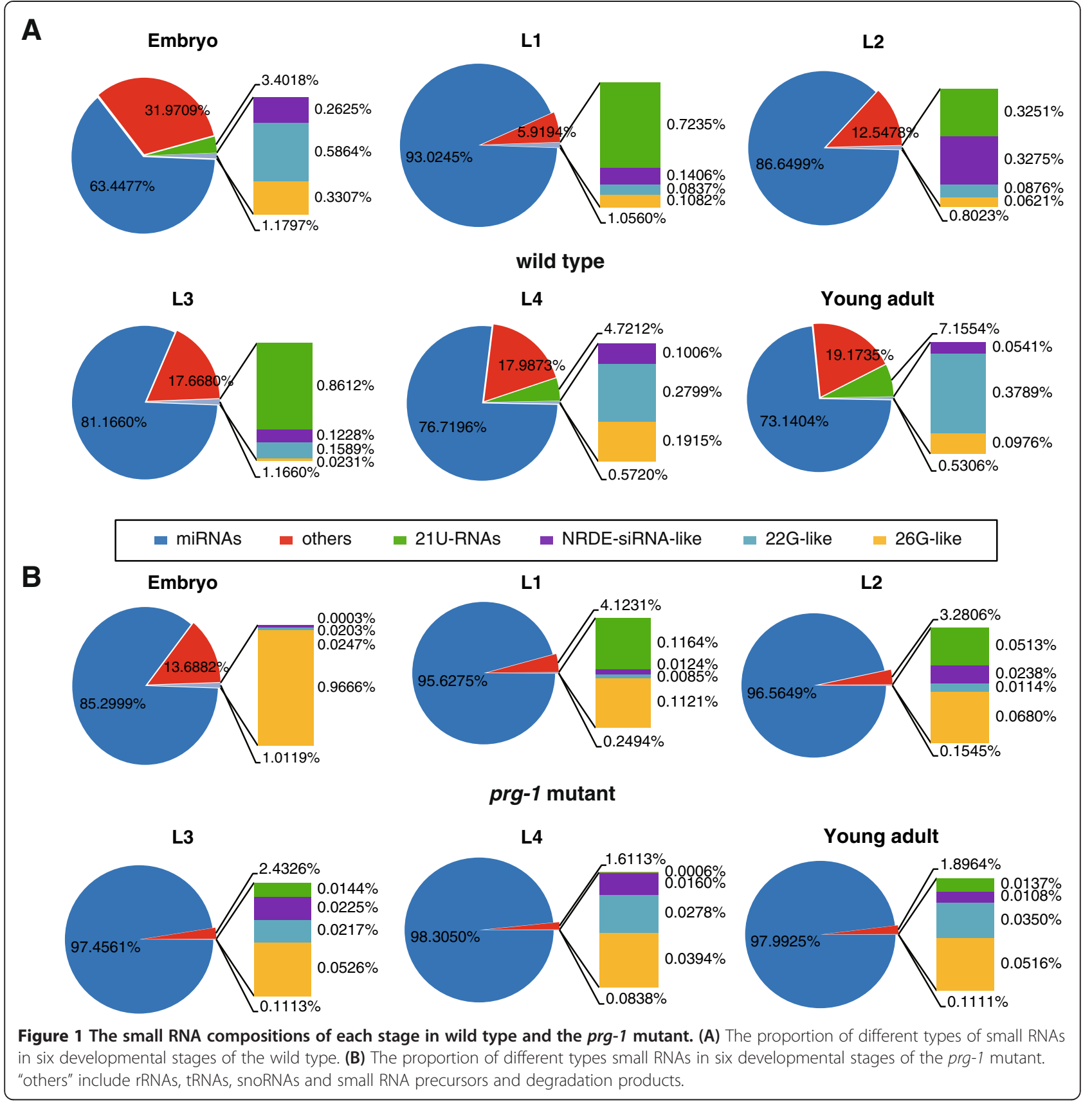

stages or in five stages. That is, in different developmental stages, the down-regulated miRNAs were almost identical. This result indicated that the influence of PRG-1 on miRNAs was independent of the developmental stage.

We selected the targets of the miRNAs which were down-regulated in all developmental stages and analyzed the functions of these targets by DAVID [33,34]. We found that these targets were related with the growth and mitochondrion (Additional file 2: Figure S1), and the outcome was similar to $\mathrm{GO}$ analysis section below.
21U-RNAs are expressed at low levels in the prg-1 mutant 21U-RNAs, another class of C. elegans non-coding small RNAs, specifically bind PRG-1 to form a complex that is important for germline function and fertility [8]. There have been reports that PRG- 1 was required for the accumulation of 21U-RNAs [8]. In our data, known $21 \mathrm{U}-$ RNAs were identified based on the list of 21U-RNAs by Bagijn et al. [35], and novel 21U-RNAs (Additional file 3) were predicted using the criteria described by Bagijn et al. [35]. The levels of nearly all 21U-RNAs at each 

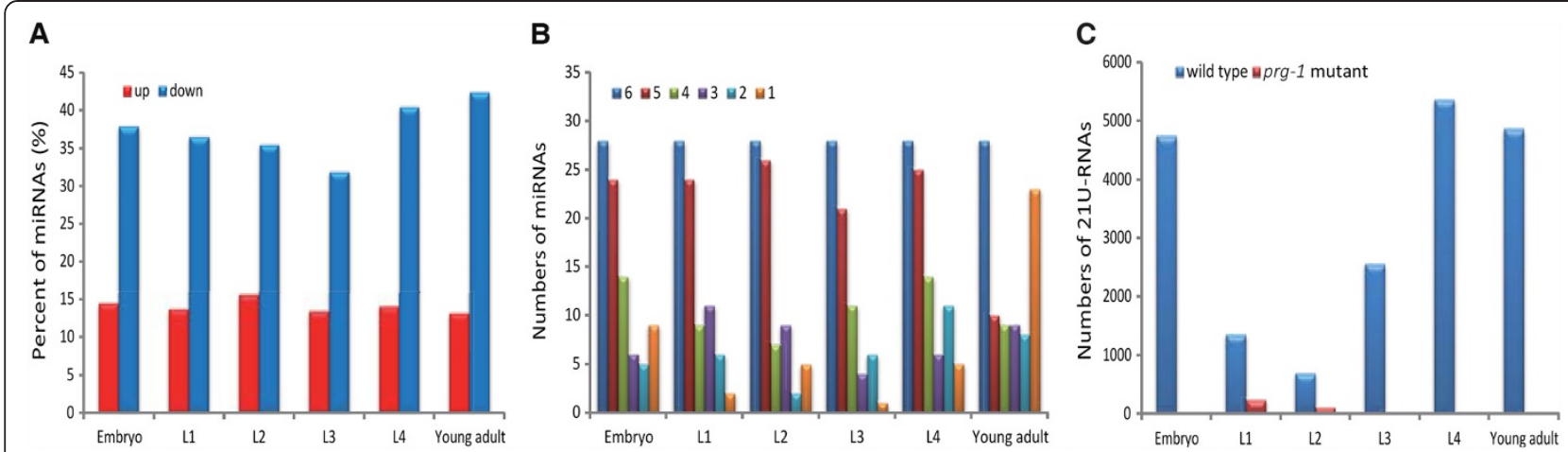

Figure 2 Differential expression of miRNAs and 21U-RNAs in each stage with and without the prg-1 mutation. (A) The proportion of changed miRNAs in six stages. "up" indicates that the expression was up-regulated more than twofold after prg-1 mutation; and "down" indicates that the expression was down-regulated more than twofold after prg-1 mutation. (B) All miRNAs were classified by the number of times (1 6) that a miRNA was decreased in different stages. The time distribution of the down-regulated miRNAs is shown for each stage. For example, the red bar shows the number of the down-regulated miRNAs that were down-regulated in five stages. Most of the down-regulated miRNAs were down-regulated in five or six stages after mutation of prg-1. Thus, the decrease in the miRNA levels was independent of the developmental stage. (C) The numbers of expressed 21U-RNAs in six stages of wild type and prg-1 mutant.

stage were dramatically reduced by the $\mathrm{prg}-1$ mutation. As presented in Figure 2C, 21U-RNAs are expressed at low levels in six stages after the mutation of $p r g-1$. Especially in L3-L4, when 21U-RNAs accumulate, 21U-RNA expression could not be detected. This result demonstrated that PRG-1 affected the expression and accumulation of 21URNAs, which supported previously published results.

\section{The expression of miRNAs and 21U-RNAs during development}

During C. elegans development, individual miRNAs have dynamic expression patterns [25]. The expression of 21 U-RNAs also changes during development $[8,25]$. To examine the entire range of expression of miRNAs and 21U-RNAs during C. elegans development in the wild type and the prg-1 mutant, we parsed the expression changes of miRNAs and 21U-RNAs between adjacent developmental stages.

As observed in Figure $3 \mathrm{~A}$ and B, $\sim 68 \%$ of known miRNAs did not show a change between adjacent development stages, approximately 205 miRNAs were expressed in both adjacent periods (Additional file 1: Table S2). Moreover, in the prg-1 mutant, expression of $\sim 87 \%$ of the miRNAs did not differ significantly during development. The adjacent stages expressed approximately 214 miRNAs (Additional file 1: Table S2).

The expression of 21U-RNAs increased during development in wild-type C. elegans (Figure 2C). However, some 21U-RNAs were not expressed from the L4 to young adult stage. This phenomenon suggested that some 21U-RNAs were not needed in the mature organism; therefore, 21U-RNAs ceased being expressed and were gradually degraded. In the prg-1 mutant, few 21URNAs could be detected, and those that were detected were low.
The general trend of $21 \mathrm{U}-\mathrm{RNAs}$ is that the types gradually increase and that their expression increases during development in the wild type.

Of the $3 \%$ of protein-coding genes that were substantially altered, approximatley $60 \sim 70 \%$ were up-regulated

PRG-1 influences the C. elegans reproductive phenotype, and phenotypic changes are directly dependent on the expression of protein-coding genes. Therefore, we expected to find some changes in gene expression in the prg-1 mutant. To study whether PRG-1 affected the expression of protein-coding genes, the mRNA expression in four stages (L1-L4) with and without a mutation in prg-1 were analyzed. We found that in L1-L4, 3.62\%, $3.58 \%, 3.53 \%$ and $6.00 \%$, respectively, of protein-coding genes were differentially expressed (Additional file 1: Table S3). Approximately $60 \sim 70 \%$ of the differentially expressed genes were up-regulated at each stage (Figure 4).

\section{The target genes of down-regulated small RNAs were up-regulated}

miRNAs are small RNAs that regulate protein-coding genes, and 21U-RNAs are reported to participate in regulating protein-coding genes [35]. In our study, miRNA and 21U-RNA expression was reduced after mutation of prg-1, and we speculated that the reduction in small RNA expression led to the elevation of expression of protein-coding genes. To verify whether the target genes of the down-regulated small RNAs were upregulated, we analyzed the target genes of the downregulated miRNAs and 21U-RNAs in four stages.

The results (Figure 5 includes $\mathrm{P}$ values from T-tests) indicated that the target genes of the down-regulated miRNAs and 21U-RNAs had higher expression in the 

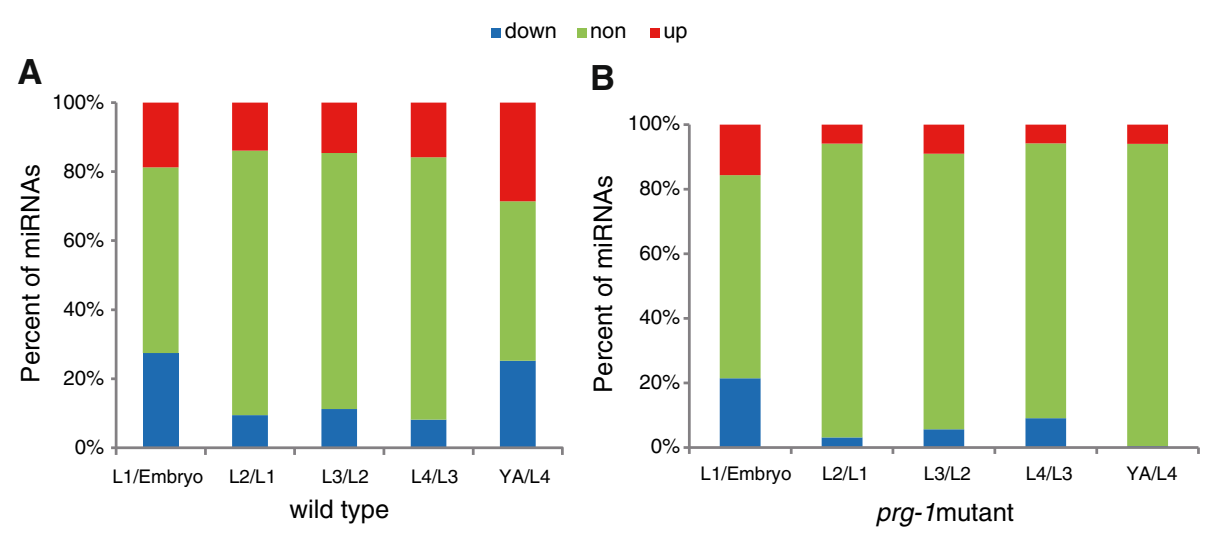

Figure 3 Differential expression of miRNAs and 21U-RNAs between adjacent developmental stages. The percent of differentially expressed miRNAs in the (A) wild type and (B) prg-1 mutant between adjacent stages. "up" indicates that the expression (for example, L1/Embryo) was more than two-fold higher in later stages; "down" indicates that the expression (for example, L1/Embryo) was more than two fold lower in later stages; and "non" indicates that the expression between adjacent stages was up-regulated and down-regulated by less than twofold.

same stages after mutation of prg-1. These findings suggest that PRG-1-dependent small RNAs affect the expression of protein-coding genes.

Significantly up-regulated genes were enriched with the substantially altered target genes of the down-regulated miRNA and 21U-RNAs

The prg-1 mutation led to a significant increase in the expression of some protein-coding genes. Meanwhile, the target genes of the down-regulated miRNA and 21URNAs were up-regulated. Therefore, we explored whether the up-regulated genes were induced by the downregulated miRNAs and 21U-RNAs. The enrichment of the differentially expressed target genes that were regulated by the down-regulated miRNAs and 21U-RNAs within the substantially up-regulated protein-coding genes was calculated.

As seen in Figure 6A, the substantially up-regulated protein-coding genes were enriched with the differentially

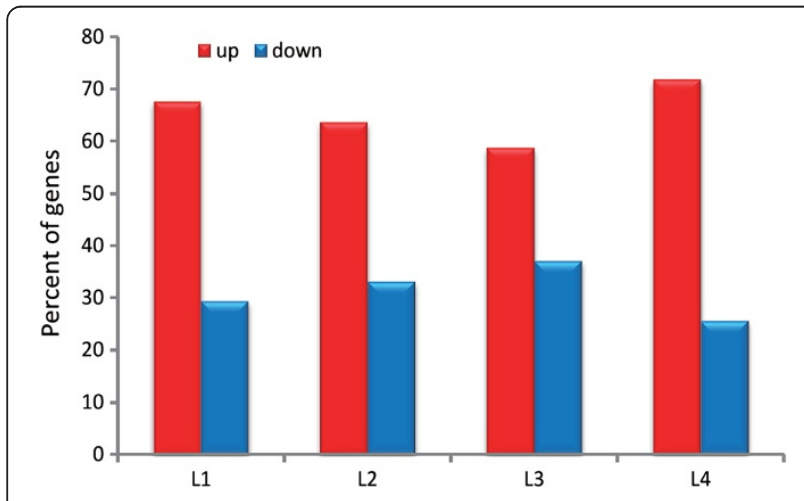

Figure 4 Differentially expressed protein-coding genes after prg-1 mutation. The proportion of up- and down-regulated proteincoding genes that were significantly changed ( $P<0.05, q<0.01$ of Storey) after prg-1 mutation is shown. expressed target genes of the down-regulated miRNAs and 21U-RNAs ( $\mathrm{P}$ values from Fisher's exact test are shown in the figure). Of the up-regulated protein-coding genes, $\sim 30 \%$ (Figure 6B) were up-regulated target genes. Namely, the prg-1 mutation increased gene expression, and the down-regulation of miRNAs and 21U-RNAs was the cause of the increased gene expression in $1 / 3$ of the substantially up-regulated protein-coding genes.

\section{PRG-1-dependent small RNAs participated in C. elegans development}

Mutation of prg-1 can affect small RNAs, thereby influencing the expression of their target genes. Alterations in the expression of target genes may change certain biological processes. To study how prg-1 affects the $C$. elegans biological phenotype, GO analysis [33,34] was performed for the up-regulated genes that were targets of the down-regulated miRNAs and 21U-RNAs in each stage.

The results (Figure 7) indicated that these target genes from different stages were all enriched in the biological processes related to growth and development. For example, some target genes were enriched in 'determination of adult life span' in L1. Target genes were also enriched in 'regulation of multicellular organism growth' in L2 and L4, as well as in 'larval development' in the L2 stages. Together, these findings illustrated that PRG-1related protein-coding genes were involved in C. elegans development. If PRG-1 was expressed at normal levels, miRNAs and 21U-RNAs would be expressed normally, and their target genes would maintain normal levels of expression. Under these conditions, C. elegans would develop into a typical mature individual. In L3 and L4, these up-regulated genes were also enriched in the biological processes of transcription and RNA metabolism. In L3 in C. elegans, a large number of small RNAs, such 


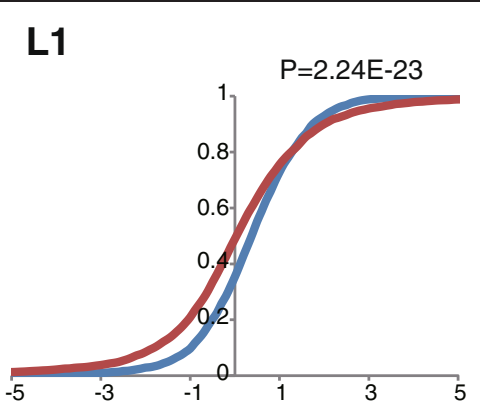

\section{L3}

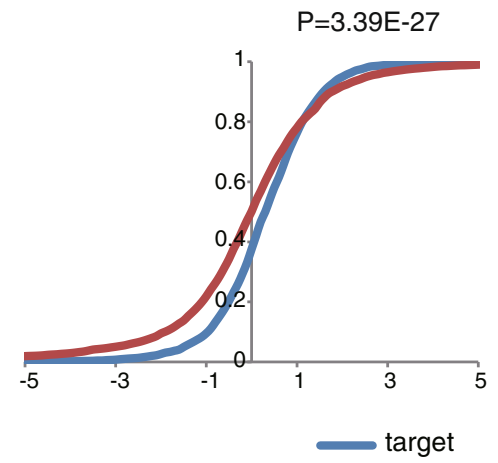

L2

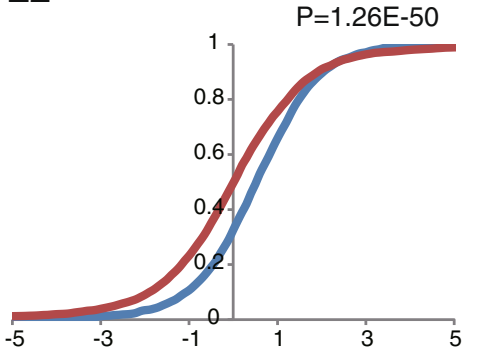

L4

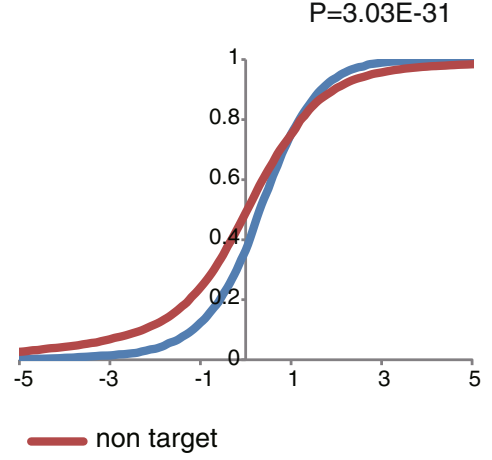

Figure $\mathbf{5}$ The cumulative distribution of the targets of the down-regulated miRNAs and 21U-RNAs. The cumulative distribution of the target and non-target genes of the down-regulated miRNAs and 21U-RNAs in L1-L4 indicated that the expression of the target genes was increased compared with that of non-target genes after prg-1 mutation.

as 21U-RNAs and 22G-RNAs, are produced, and the regulatory functions of small RNAs are reinforced. Both of these behaviors require a large number of transcriptional events. Therefore, these requirements explain the enrichment of genes involved in transcription- and RNA metabolism-related biological processes in the L3 and L4 stages.

\section{Three cases of verified, decreased miRNA targets}

We systematically analyzed the function of the predicted target genes of the down-regulated miRNAs via DAVID and found that these target genes were related to development. Then, we downloaded the verified miRNA targets from the miRTarBase website [36] and selected three examples of target genes of the decreased miRNAs for analysis. miR-63-3p, miR-66-5p, miR-87-3p, miR-233-3p and miR-234-3p were decreased in the L1-L4 stages in the prg1 mutant. At the same time, their target, K06A9.1, displayed more than two-fold up-regulation (Figure 8). GO identified K06A9.1 as an intrinsic component of the membrane (GO:0031224). miR-60-3p was decreased in L1, L3 and L4, and its target, $\mathrm{K} 12 \mathrm{H} 4.4$, had a greater than twofold increase in the corresponding stages. miR-80-3p was
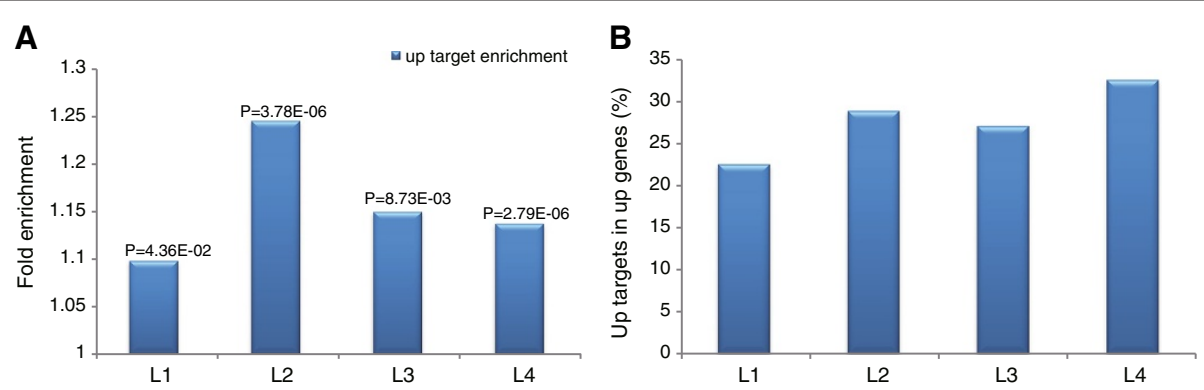

Figure 6 The substantially increased protein-coding genes were enriched with targets of the down-regulated miRNAs and 21U-RNAs. (A) The up-regulated genes were enriched with the differentially expressed target genes of the down-regulated miRNAs and 21U-RNAs at the corresponding stages. P values were calculated using Fisher's exact test. (B) The percentage of up-regulated targets among the up-regulated protein-coding genes in the corresponding stages. 


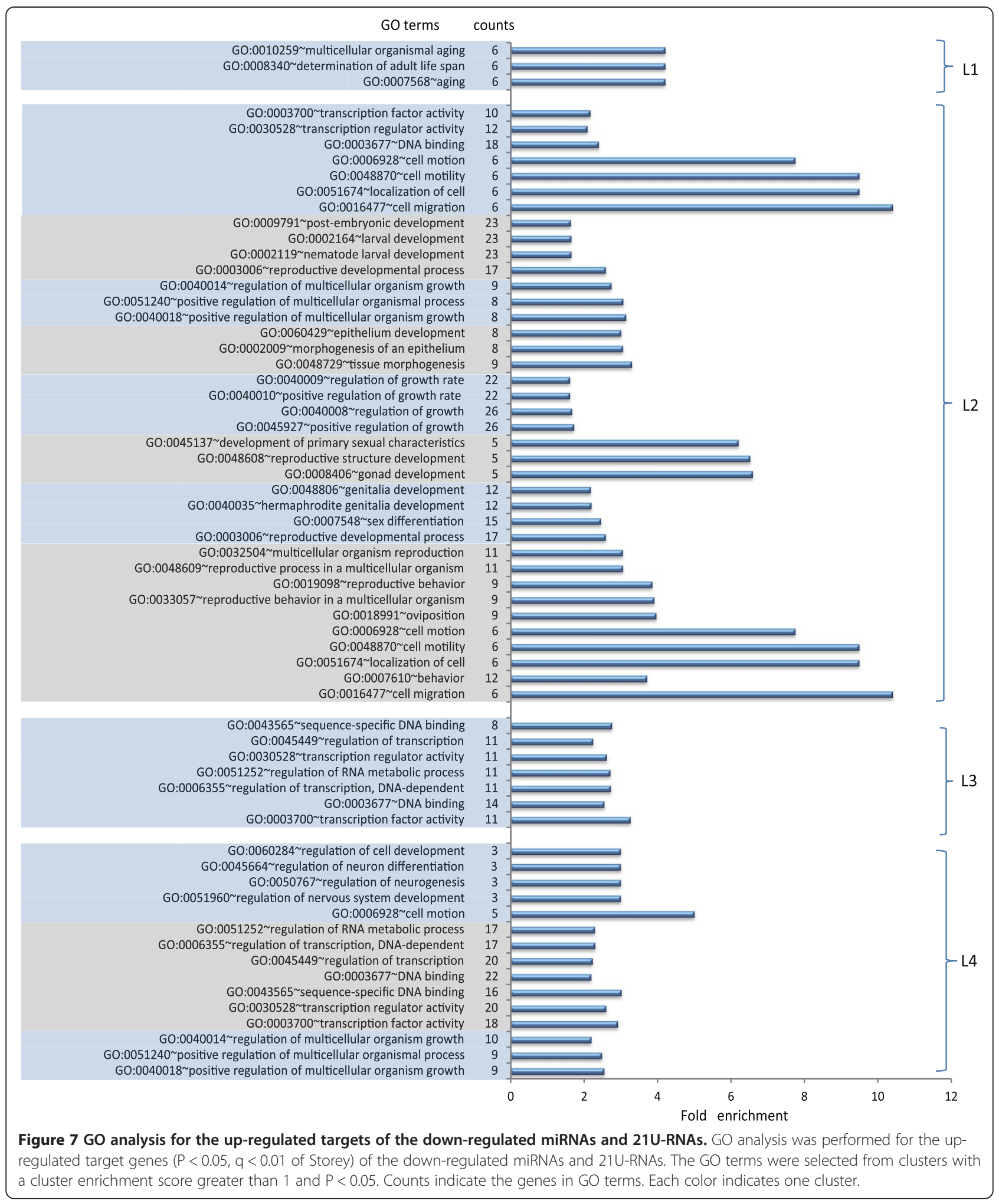

down-regulated in L2-L4, and the expression of its target, B0361.9, increased more than two-fold after the mutation of prg-1. K12H4.4 and B0361.9 are both implicated in the development of C. elegans.

\section{Discussion}

\section{Composition of other small RNAs}

Our results included small RNAs that were not the focus of the current study, such as rRNAs (ribosomal RNAs), 


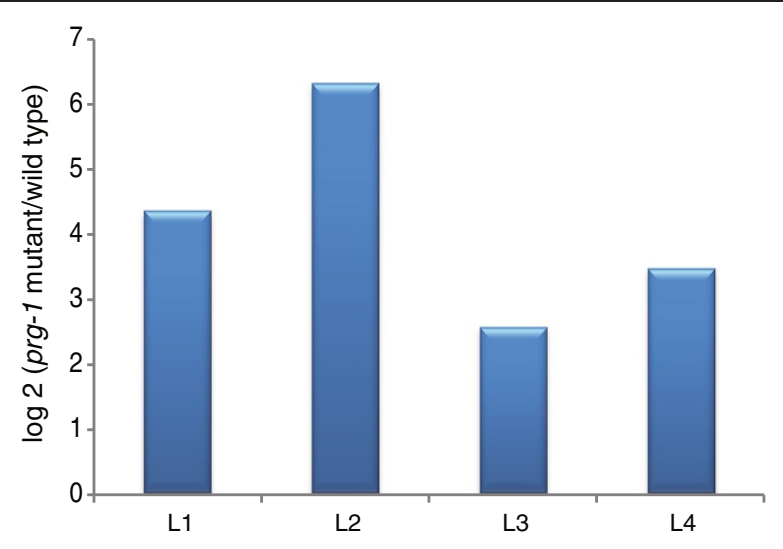

Figure 8 Fold change of a target, K06A9.1, in L1-L4. miR-63-3p, miR-66-5p, miR-87-3p, miR-233-3p and miR-234-3p were decreased after mutation of prg-1. Their target, K06A9.1, showed an increase of more than twofold of that in L1-L4. prg-1 mutant and wild type indicate the expression of K06A9.1 in the prg-1 mutant and wild type, respectively.

tRNAs (transfer RNAs), and snoRNAs (small nucleolar RNAs), as well as small RNA precursors and degradation products. In Figure 1, these RNAs (termed "other") in the prg-1 mutant had remarkable decreases in all stages relative to the wild-type $C$. elegans. It is likely that our results included types of small RNAs that have not yet been recognized, and these unknown small RNAs may have disappeared in the prg-1 mutant. Alternately, the difference may be explained by the processes for preparing the small RNAs and sequencing.

\section{G-like and 26G-like small RNAs}

In wild-type C. elegans (Figure 1A), the proportion of 21U-RNAs was reduced between the L1 and L2 stages. This phenomenon could be explained by an absence of expression of novel 21U-RNAs and prioritizing the degradation of $21 \mathrm{U}-\mathrm{RNAs}$ during that period or to the fact that the rate at which $21 \mathrm{U}$-RNAs were generated was less than the speed of their degradation. Either explanation would lead to an overall reduction in 21U-RNAs.

The present report has demonstrated that 21U-RNAmediated silencing in the $C$. elegans germline results in secondary siRNA-dependent silencing of a 'piRNA sensor' [35]. Thus, the 21U-RNA-mediated silencing pathway completes the supervisory function through a secondary siRNA, known as 22G-RNAs which are RNAdependent RNA polymerase (RdRP)-generated RNAs [35,37]. 22G-RNAs are predominantly $22 \mathrm{nt}$ in length and contain a $5^{\prime}-\mathrm{G}$ that is triphosphorylated [38]. As our data indicate, we only obtained 5 '-monophosphate small RNAs; and no 22G-RNAs were detected, so we defined these 22 nt small RNA which selected by the targets of 22G-RNAs as 22G-like small RNA. 26G-like small RNAs also defined in a similar method. However, as the wild- type results show in Figure 1A, the expression of 22Glike small RNAs gradually increased during development, as did the expression of $21 \mathrm{U}$-RNAs. Therefore, it was probable that some $5^{\prime}$-monophosphate 22G-RNAs were present and participated in downstream regulation of the 21U-RNA-mediated pathway.

There are two distinct classes of 26G-RNAs in C. elegans. One class is enriched in oocytes and embryos and associates with ERGO-1 [12,15,39]. The other class associates with ALG-3 and ALG-4 during spermatogenesis $[10,15]$. Both classes are thought to function by triggering the formation of 22G-RNAs and subsequent silencing of target mRNAs [24,40]. In wild-type C. elegans, the expression of 26G-like small RNAs first decreased and then increased as development progresses. A similar expression pattern was also observed in the prg-1 mutant; however, the expression was lower than that of the wild type. Interestingly, in the prg-1 mutant, the expression of 22G-like small RNAs increased during development (Figure 1B). If the prg- 1 mutation is present, the 21U-RNA-mediated pathway should be blocked, and the expression of 22G-like small RNAs, which are expressed downstream of this pathway, should decrease. However, the prg-1 mutation did not affect the 26G-RNAmediated pathway because the expression pattern of the 26G-RNAs did not change. The downstream 22G-like small RNAs were expressed normally and increased during development in the prg-1 mutant.

PRG-1-dependent, down-regulated miRNAs and 21U-RNAs are responsible for $1 / 3$ of the expression of the substantially up-regulated genes

Approximately $60 \sim 70 \%$ of the significantly altered genes exhibited up-regulation after the mutation of prg1. Of these, $1 / 3$ were induced by the down-regulated miRNAs and $21 U-R N A s$. The remaining substantially up-regulated protein-coding genes might be directly regulated by the PRG-1 protein; the target genes of the small RNAs could regulate the other mRNAs. The internal control network of C. elegans is complex and cannot be fully explained by the $p r g-1$ pathway alone.

\section{Conclusions}

We analyzed small RNAs (from embryo, L1, L2, L3, L4, and young adult) and mRNAs (from L1, L2, L3, and L4) in a prg-1 mutant using high-throughput sequencing. By analyzing wild-type small RNAs and mRNAs of the corresponding stages found in the NCBI database, we found decreased miRNA and 21U-RNA levels in six stages after mutation of $p r g-1$. In the prg-1 mutant, approximately $3 \%$ of the protein-coding genes showed differential expression, of which approximately $60 \sim 70 \%$ exhibited up-regulation. Approximately $1 / 3$ of the substantially up-regulated protein- 
coding genes were target genes of the down-regulated miRNAs and 21U-RNAs.

\section{Methods}

Small RNA and mRNA preparation and high-throughput sequencing

The nematode strain used in this study was the $C$. elegans prg-1 mutant (wm161). Worms were cultured with the bacterial strain OP50 on nematode growth medium. All strains were grown at $20^{\circ} \mathrm{C}$.

As described by Deng et al. [41], we collected small RNAs (embryo, L1, L2, L3, L4, and young adult) and mRNAs (L1L4) at different stages. Total RNA was extracted from each of the six different developmental stages using the Trizol protocol. Small RNAs were size-selected by gel electrophoresis, and we used poly(A) to extract L1-L4 mRNA. Then, we submitted small RNAs from six stages and mRNA from four stages for high-throughput sequencing.

\section{Small RNA classification}

First, we removed the sequences with lengths $<18$ nt and removed the simple repeat sequences that had a singlebase content greater than $85 \%$. Then, small RNAs were mapped to the C. elegans genome (ce10), with allowances for 0 mismatches using the software Bowtie.

The known miRNAs were selected from the perfectly mapped small RNAs using miRDeep2 [30]. 21U-RNAs were assessed using perfect matching to known $21 \mathrm{U}$ RNAs from the perfectly matched small RNAs. We predicted the novel 21U-RNAs as Bagijn et al. described [35]. We also selected type 2 21U-RNAs [42].

The small RNAs that remained after we removed the miRNAs and 21U-RNAs were classified as described by Zhang et al. [38]. Briefly, published targets of different class siRNAs were parsed. The target genes of WAGO1-12-associated 22G-RNAs [11] and of CSR-1-associated 22G-RNAs [14] were used to select 22G-like small RNAs. The target genes of ERGO-1 [12] and of ALG-3/ 4-associated 26G-RNAs [10,15] were used to select the 26G-like small RNAs. The NRDE-like small RNAs were those that were identical to the NRDE-3-associated siRNAs [38]. The remaining perfectly mapped small RNAs were called 'others'.

We used DEGseq [31] and GFOLD [32] to analyze miRNAs expression. We chose miRNAs which had more than two-fold difference in expression $(\mathrm{P}<0.001, \mathrm{q}<$ 0.01 of Storey) from DEGseq, and miRNAs which had more than two-fold difference in expression (GFOLD score $>0$ for up-regulation and GFOLD score $<0$ for down-regulation) from GFOLD outcomes. Then we obtained the intersection of up-regulated miRNAs and down-regulated miRNAs for each stage from the chosen miRNAs, respectively. 21U-RNAs (known 21U-RNAs) reads were normalized to the total known miRNA reads.
Almost all of 21U-RNAs could not be detected after prg1 mutation, so we considered these 21U-RNAs were down-regulated. We considered 21U-RNAs expression if the expression is greater than 1 after normalization.

\section{mRNA data analyses and target gene screening}

We used eight sets of mRNA data. The wild-type mRNAs (L1-L4) were downloaded from the NCBI database (GSE22410) [23]. The other four sets consisted of our sequencing data. Tophat and Cufflinks [43] were used to assemble the wild-type and prg-1-mutant mRNAs. Cuffdiff and DEGseq [31] were used to calculate the differential expression of protein-coding genes with and without the prg-1 mutation, and we selected genes which had more than two-fold difference in expression $(\mathrm{P}<0.05, \mathrm{q}<0.01$ of Storey) from DEGseq outcomes. The intersection of genes which we selected from DEGseq outcomes and genes which had more than two-fold difference in expression $(\mathrm{P}<0.05)$ from Cuffdiff outcomes was defined as differentially expressed genes. The following analyses were based on $\mathrm{P}<0.05$ and $\mathrm{q}<0.01$ of Storey.

The list of miRNA target genes was downloaded from microRNA.org. The target genes of the down-regulated miRNAs were chosen when five or more miRNAs had the same target genes. We predicted 21U-RNA candidate target genes in the C. elegans mRNAs and allowed for up to three mismatches [35].

\section{Gene ontology analyses}

The up-regulated genes with $\mathrm{P}<0.05$ ( $\mathrm{q}<0.01$ of Storey) were selected from the target genes of the down-regulated miRNAs and 21U-RNAs. The selected genes were input into DAVID [33,34], which sorted these genes into functionally related clusters. The clusters with an enrichment score greater than 1 were chosen. The $\mathrm{P}<0.05 \mathrm{GO}$ terms were selected from the high enrichment score clusters.

\section{Availability of supporting data}

The small RNAs and mRNAs data of wild type used in this study were downloaded from NCBI gene Expression Omnibus (http://www.ncbi.nlm.nih.gov/geo/) under accession number: GSE22410 and GSE11738; and small RNAs and mRNAs data of the prg-1 mutant were deposited in the Gene Expression Omnibus with the following accession number: GSE56274. The additional files and information are available at the website: http://www.regulatoryrna.org/pub/cel_smallRNA/index.html.

\section{Additional files}

Additional file 1: Table S1. - miRNA expression after prg-1 mutation. Table S2 - miRNA expression during development. Table S3 - Expression of protein-coding genes after prg-1 mutation ( $P<0.05, q<0.01$ of Storey). 
Additional file 2: Figure S1. GO analysis for the targets of down-regulated miRNAs in all developmental stages. We selected the targets of the miRNAs which are down-regulated in all developmental stages and analyzed the functions of these targets by DAVID. Counts indicated the genes in GO terms.

\section{Additional file 3: The novel 21U-RNAs.}

\section{Competing interests}

The authors declare that they have no competing interests.

\section{Authors' contributions}

RC, SH and DH conceived and designed the study. DC and TX performed the experimental work. JW carried out data analysis. DC, XS and PZ contributed to the transcriptome data analysis. JW, DC and TX drafted the manuscript. SH reviewed the manuscript. RC and DH supervised the study. All authors read and approved the final manuscript.

\section{Acknowledgements}

The strain prg-1 mutant (wm161) that was used in this study was obtained from the Caenorhabditis Genetic Center. We thank our labmates for many helpful discussions and comments on the manuscript. This project was supported by the National Key Basic Research \& Development Program under Grant No. 2011CB504605, by the National High Technology Research and Development Program under Grant No. 2014AA021103, by the National Natural Science Foundation of China (NSFC grant no. 31090253, 31210103912), partially by a grant (No. O529YX5105) from the Key Laboratory of the Zoological Systematics and Evolution of the Chinese Academy of Sciences, and by National Science Fund for Fostering Talents in Basic Research (Special subjects in animal taxonomy, NSFC-J1210002). The computing resource was supported by HPC Platform, Scientific Information Center, Institute of Zoology, CAS, China.

\section{Author details}

'School of Life Science, Hebei University, Hebei 071002, People's Republic of China. ${ }^{2}$ Key Laboratory of Zoological Systematics and Evolution, Institute of Zoology, Chinese Academy of Sciences, Beijing 100101, People's Republic of China. ${ }^{3}$ Laboratory of Bioinformatics and Noncoding RNA, Institute of Biophysics, Chinese Academy of Sciences, Beijing 100101, People's Republic of China. ${ }^{4}$ College of Life Science, Yuncheng University, Yuncheng, Shanxi 044000, People's Republic of China.

Received: 30 January 2014 Accepted: 24 April 2014

Published: 30 April 2014

\section{References}

1. Tomari Y, Du T, Haley B, Schwarz DS, Bennett R, Cook HA, Koppetsch BS, Theurkauf WE, Zamore PD: RISC assembly defects in the Drosophila RNAi mutant armitage. Cell 2004, 116(6):831-841.

2. Pham JW, Pellino JL, Lee YS, Carthew RW, Sontheimer EJ: A Dicer-2dependent 80 s complex cleaves targeted mRNAs during RNAi in Drosophila. Cell 2004, 117(1):83-94.

3. Chendrimada TP, Gregory Rl, Kumaraswamy E, Norman J, Cooch N, Nishikura K, Shiekhattar R: TRBP recruits the Dicer complex to Ago2 for microRNA processing and gene silencing. Nature 2005, 436(7051):740-744.

4. Liu Q, Rand TA, Kalidas S, Du F, Kim HE, Smith DP, Wang X: R2D2, a bridge between the initiation and effector steps of the Drosophila RNAi pathway. Science 2003, 301(5641):1921-1925.

5. Grishok A: Biology and Mechanisms of Short RNAs in Caenorhabditis elegans. Adv Genet 2013, 83:1-69.

6. Yigit E, Batista PJ, Bei Y, Pang KM, Chen CC, Tolia NH, Joshua-Tor L, Mitani S, Simard MJ, Mello CC: Analysis of the C. elegans Argonaute family reveals that distinct Argonautes act sequentially during RNAi. Cell 2006, 127(4):747-757.

7. Das PP, Bagijn MP, Goldstein LD, Woolford JR, Lehrbach NJ, Sapetschnig A, Buhecha HR, Gilchrist MJ, Howe KL, Stark R, Matthews N, Berezikov E, Ketting RF, Tavaré S, Miska EA: Piwi and piRNAs act upstream of an endogenous siRNA pathway to suppress Tc3 transposon mobility in the Caenorhabditis elegans Germline. Mol Cell 2008, 31(1):79-90,

8. Batista PJ, Ruby JG, Claycomb JM, Chiang R, Fahlgren N, Kasschau KD, Chaves DA, Gu W, Vasale JJ, Duan S, Conte D Jr, Luo S, Schroth GP. Carrington JC, Bartel DP, Mello CC: PRG-1 and 21U-RNAs interact to form the piRNA complex required for fertility in C. elegans. Mol Cell 2008, 31(1):67-78.
9. Grishok A, Pasquinelli AE, Conte D, Li N, Parrish S, Ha I, Baillie DL, Fire A, Ruvkun G, Mello CC: Genes and mechanisms related to RNA interference regulate expression of the small temporal RNAs that control C. elegans developmental timing. Cell 2001, 106(1):23-34.

10. Conine CC, Batista PJ, Gu W, Claycomb JM, Chaves DA, Shirayama M, Mello CC: Argonautes ALG-3 and ALG-4 are required for spermatogenesisspecific 26G-RNAs and thermotolerant sperm in Caenorhabditis elegans. Proc Natl Acad Sci U S A 2010, 107(8):3588-3593.

11. Gu W, Shirayama M, Conte D Jr, Vasale J, Batista PJ, Claycomb JM, Moresco JJ, Youngman EM, Keys J, Stoltz MJ, Chen CC, Chaves DA, Duan S, Kasschau KD, Fahlgren N, Yates JR, Mitani S, Carrington JC, Mello CC: Distinct argonaute-mediated 22G-RNA pathways direct genome surveillance in the C. elegans germline. Mol Cell 2009, 36(2):231-244.

12. Vasale JJ, Gu W, Thivierge C, Batista PJ, Claycomb JM, Youngman EM, Duchaine TF, Mello CC, Conte D Jr: Sequential rounds of RNA-dependent RNA transcription drive endogenous small-RNA biogenesis in the ERGO-1/ Argonaute pathway. Proc Natl Acad Sci U S A 2010, 107(8):3582-3587.

13. Shirayama M, Seth M, Lee HC, Gu W, Ishidate T, Conte D Jr, Mello CC: piRNAs initiate an epigenetic memory of nonself RNA in the C. elegans germline. Cell 2012, 150(1):65-77.

14. Claycomb JM, Batista PJ, Pang KM, Gu W, Vasale JJ, van Wolfswinkel JC, Chaves DA, Shirayama M, Mitani S, Ketting RF, Conte D Jr, Mello CC: The Argonaute CSR-1 and its 22G-RNA cofactors are required for holocentric chromosome segregation. Cell 2009, 139(1):123-134.

15. Han T, Manoharan AP, Harkins TT, Bouffard P, Fitzpatrick C, Chu DS, Thierry-Mieg $D$, Thierry-Mieg J, Kim JK: $26 \mathrm{G}$ endo-siRNAs regulate spermatogenic and zygotic gene expression in Caenorhabditis elegans. Proc Natl Acad Sci U S A 2009, 106(44):18674-18679.

16. Wedeles CJ, Wu MZ, Claycomb JM: A multitasking Argonaute: exploring the many facets of C. elegans CSR-1. Chromosome Res 2013, 21(6-7):573-586.

17. Wang G, Reinke V: A C. elegans Piwi, PRG-1, regulates 21U-RNAs during spermatogenesis. Curr Biol 2008, 18(12):861-867.

18. Ruby JG, Jan C, Player C, Axtell MJ, Lee W, Nusbaum C, Ge H, Bartel P: Large-scale sequencing reveals 21U-RNAs and additional microRNAs and endogenous siRNAs in C. elegans. Cell 2006, 127(6):1193-1207.

19. Ohara T, Sakaguchi $Y$, Suzuki T, Ueda H, Miyauchi K, Suzuki T: The 3 ' termini of mouse Piwi-interacting RNAs are 2'-O-methylated. Nat Struct Mol Biol 2007, 14(4):349-350.

20. Saito K, Sakaguchi Y, Suzuki T, Suzuki T, Siomi H, Siomi MC: Pimet, the Drosophila homolog of HEN1, mediates 2'-O-methylation of Piwi- interacting RNAs at their 3' ends. Genes Dev 2007, 21(13):1603-1608.

21. Horwich MD, Li C, Matranga C, Vagin V, Farley G, Wang P, Zamore PD: The Drosophila RNA methyltransferase, DmHen1, modifies germline piRNAs and single-stranded siRNAs in RISC. Curr Biol 2007, 17(14):1265-1272.

22. Kirino Y, Mourelatos Z: Mouse Piwi-interacting RNAs are 2'-O-methylated at their 3' termini. Nat Struct Mol Biol 2007, 14(4):347-348.

23. Lamm AT, Stadler MR, Zhang H, Gent Jl, Fire AZ: Multimodal RNA-seq using single-strand, double-strand, and CircLigase-based capture yields a refined and extended description of the $\mathrm{C}$. elegans transcriptome. Genome Res 2011, 21(2):265-275.

24. Shi Z, Montgomery TA, Qi Y, Ruvkun G: High-throughput sequencing reveals extraordinary fluidity of miRNA, piRNA, and siRNA pathways in nematodes. Genome Res 2013, 23(3):497-508.

25. Kato M, de Lencastre A, Pincus Z, Slack FJ: Dynamic expression of small non-coding RNAs, including novel microRNAs and piRNAs/21U-RNAs, during Caenorhabditis elegans development. Genome Bio/ 2009, 10(5):R54.

26. Lau NC, Lim LP, Weinstein EG, Bartel DP: An abundant class of tiny RNAs with probable regulatory roles in Caenorhabditis elegans. Science 2001, 294(5543):858-862

27. Lee RC, Ambros V: An extensive class of small RNAs in Caenorhabditis elegans. Science 2001, 294(5543):862-864.

28. Lim LP, Lau NC, Weinstein EG, Abdelhakim A, Yekta S, Rhoades MW, Burge CB, Bartel DP: The microRNAs of Caenorhabditis elegans. Genes Dev 2003 17(8):991-1008

29. Gerstein MB, Lu ZJ, Van Nostrand EL, Cheng C, Arshinoff BI, Liu T, Yip KY, Robilotto R, Rechtsteiner A, Ikegami K, Alves P, Chateigner A, Perry M, Morris M, Auerbach RK, Feng X, Leng J, Vielle A, Niu W, Rhrissorrakrai K, Agarwal A, Alexander RP, Barber G, Brdlik CM, Brennan J, Brouillet JJ, Carr A, Cheung MS, Clawson H, Contrino S, et al: Integrative analysis of the Caenorhabditis elegans genome by the modENCODE project. Science 2010, 330(6012):1775-1787. 
30. Friedlander MR, Mackowiak SD, Li N, Chen W, Rajewsky N: miRDeep2 accurately identifies known and hundreds of novel microRNA genes in seven animal clades. Nucleic Acids Res 2012, 40(1):37-52.

31. Wang L, Feng Z, Wang X, Wang X, Zhang X: DEGseq: an R package for identifying differentially expressed genes from RNA-seq data. Bioinformatics 2010, 26(1):136-138.

32. Feng J, Meyer CA, Wang Q, Liu JS, Shirley Liu X, Zhang Y: GFOLD: a generalized fold change for ranking differentially expressed genes from RNA-seq data. Bioinformatics 2012, 28(21):2782-2788.

33. da Huang W, Sherman BT, Lempicki RA: Systematic and integrative analysis of large gene lists using DAVID bioinformatics resources. Nat Protoc 2009, 4(1):44-57.

34. da Huang W, Sherman BT, Lempicki RA: Bioinformatics enrichment tools: paths toward the comprehensive functional analysis of large gene lists. Nucleic Acids Res 2009, 37(1):1-13.

35. Bagijn MP, Goldstein LD, Sapetschnig A, Weick EM, Bouasker S, Lehrbach NJ, Simard MJ, Miska EA: Function, targets, and evolution of Caenorhabditis elegans piRNAs. Science 2012, 337(6094):574-578.

36. Hsu SD, Lin FM, Wu WY, Liang C, Huang WC, Chan WL, Tsai WT, Chen GZ, Lee CJ, Chiu CM, Chien CH, Wu MC, Huang CY, Tsou AP, Huang HD: miRTarBase: a database curates experimentally validated microRNAtarget interactions. Nucleic Acids Res 2011, 39(Database issue):D163-D169.

37. Lee HC, Gu W, Shirayama M, Youngman E, Conte D Jr, Mello CC: C. elegans piRNAs mediate the genome-wide surveillance of germline transcripts. Cell 2012, 150(1):78-87.

38. Zhang C, Montgomery TA, Gabel HW, Fischer SE, Phillips CM, Fahlgren N, Sullivan CM, Carrington JC, Ruvkun G: mut-16 and other mutator class genes modulate $22 \mathrm{G}$ and $26 \mathrm{G}$ siRNA pathways in Caenorhabditis elegans. Proc Natl Acad Sci U S A 2011, 108(4):1201-1208.

39. Fischer SE, Montgomery TA, Zhang C, Fahlgren N, Breen PC, Hwang A, Sullivan CM, Carrington JC, Ruvkun G: The ERI-6/7 helicase acts at the first stage of an siRNA amplification pathway that targets recent gene duplications. PLoS Genet 2011, 7(11):e1002369.

40. Kamminga LM, van Wolfswinkel JC, Luteijn MJ, Kaaij LJ, Bagijn MP, Sapetschnig A, Miska EA, Berezikov E, Ketting RF: Differential impact of the HEN 1 homolog HENN-1 on 21U and 26G RNAs in the germline of Caenorhabditis elegans. PLoS Genet 2012, 8(7):e1002702.

41. Deng W, Zhu X, Skogerbo G, Zhao Y, Fu Z, Wang Y, He H, Cai L, Sun H, Liu C, Li B, Bai B, Wang J, Jia D, Sun S, He H, Cui Y, Wang Y, Bu D, Chen R: Organization of the Caenorhabditis elegans small non-coding transcriptome: genomic features, biogenesis, and expression. Genome Res 2006, 16(1):20-29.

42. Gu W, Lee HC, Chaves D, Youngman EM, Pazour GJ, Conte D Jr, Mello CC: CapSeq and CIP-TAP Identify Pol II start sites and reveal capped small RNAs as C. elegans piRNA precursors. Cell 2012, 151(7):1488-1500.

43. Trapnell C, Roberts A, Goff L, Pertea G, Kim D, Kelley DR, Pimentel H, Salzberg SL, Rinn JL, Pachter L: Differential gene and transcript expression analysis of RNA-seq experiments with TopHat and Cufflinks. Nat Protoc 2012, 7(3):562-578.

\section{Submit your next manuscript to BioMed Central and take full advantage of:}

- Convenient online submission

- Thorough peer review

- No space constraints or color figure charges

- Immediate publication on acceptance

- Inclusion in PubMed, CAS, Scopus and Google Scholar

- Research which is freely available for redistribution

Submit your manuscript at www.biomedcentral.com/submit
C Biomed Central 